\title{
Oligopoly with network effects: Firm-specific versus single network
}

DOI:

10.1007/s00199-019-01229-0

\section{Document Version}

Accepted author manuscript

Link to publication record in Manchester Research Explorer

\section{Citation for published version (APA):}

Amir, R., Evstigneev, I., \& Gama, A. (2019). Oligopoly with network effects: Firm-specific versus single network. Economic Theory. https://doi.org/10.1007/s00199-019-01229-0

\section{Published in:}

Economic Theory

\section{Citing this paper}

Please note that where the full-text provided on Manchester Research Explorer is the Author Accepted Manuscript or Proof version this may differ from the final Published version. If citing, it is advised that you check and use the publisher's definitive version.

\section{General rights}

Copyright and moral rights for the publications made accessible in the Research Explorer are retained by the authors and/or other copyright owners and it is a condition of accessing publications that users recognise and abide by the legal requirements associated with these rights.

\section{Takedown policy}

If you believe that this document breaches copyright please refer to the University of Manchester's Takedown Procedures [http://man.ac.uk/04Y6Bo] or contact uml.scholarlycommunications@manchester.ac.uk providing relevant details, so we can investigate your claim.

\section{OPEN ACCESS}




\title{
Oligopoly with network effects: Firm-specific versus single network*
}

\author{
Rabah Amir† Igor Evstigneev ${ }^{\ddagger}$ and Adriana Gama ${ }^{\S}$
}

\begin{abstract}
We consider symmetric oligopolies with positive network effects where each firm has its own proprietary network, which is incompatible with that of its rivals. We provide minimal conditions for the existence of (non-trivial) symmetric equilibrium in a general setting. We analyze the viability of industries with firm-specific networks, and show that the prospects for successful launch decrease with more firms in the market. This is a major reversal from the case of single-network industries. A central part of the paper compares the viability and market performance of industries with compatible and incompatible networks, and shows that viability, output, (endogenous) demand, and social welfare are higher for the former. However, the comparison of industry price, profit and consumer surplus requires respective qualifications, of a general nature for the former two but not for the latter. Overall, these results provide theoretical grounding in a general but not universal sense for the conventional view that compatibility leads to superior performance, which was hitherto based on case studies and stylized facts.
\end{abstract}

JEL codes: C72, D43, L13, L14.

Keywords and phrases: network effects, network industries, demand-side economies of scale, compatibility, incompatibility.

${ }^{*}$ The authors are grateful to Jean Gabszewicz, Filomena Garcia, Gautam Gowrisankaran, Natalia Lazzati, Ana Elisa Pereira, Joana Resende, Stanley Reynolds, and John Wooders, as well as three anonymous referees, for helpful feedback and suggestions on the subject and the contents of this paper.

${ }^{\dagger}$ Department of Economics, University of Iowa, Iowa City, IA 52242, USA and School of Business and Economics, Universidad de los Andes, Chile (e-mail: rabah-amir@uiowa.edu).

${ }^{\ddagger}$ Economics Department, University of Manchester (e-mail: igor.evstigneev@manchester.ac.uk ).

${ }^{\S}$ Centro de Estudios Económicos, El Colegio de México, Mexico (e-mail: agama@colmex.mx). 


\section{Introduction}

Industries with network externalities are characterized by a complex demand structure wherein consumers' individual demands are positively interdependent: a consumer's willingness to pay depends in a significant way on the number of consumers who are expected to purchase the same product. Rohlfs (1974) pioneered the study of such demand systems and proposed a simple and tractable model for dealing with such industries. Katz and Shapiro (1985) provided the first study of network industries under imperfect competition. ${ }^{1}$ To reduce the model to a static framework, they proposed a notion of Cournot equilibrium with an endogenous inverse demand function that reflects economy-wide rational expectations about the right market size. They investigated two different models: industry-wide and firm-specific networks. The former features goods that are perfectly compatible across firms, and is thus a single-network industry. In the latter, two goods produced by two different firms are completely incompatible, so each network is firm-specific. ${ }^{2}$ Amir and Lazzati (2011), henceforth AL (2011), provide an extensive analysis of the first model.

In short, the present paper aims to perform the same task for the second model, and to provide a comparative study of the two models. As such, this paper provides an extensive theoretical underpinning for the widely held view that firm-specific networks tend to constitute a transient phase in the development of network industries. So far, while the evidence behind this key stylized fact laid out in such influential books as Shapiro and Varian (1998) and Rohlfs (2003) has been broadly received as convincing, no theoretical study has confirmed the superiority in market performance of a single network (or full compatibility). As a short preview of our results, we report that our theoretical analysis largely vindicates this consensus, unambiguously so as far as industry viability and social welfare are concerned. Nevertheless, for industry price, profit and consumer surplus, non-universal conditions of a general nature on market primitives are critically needed, as argued via simple examples.

A diverse set of factors might lie behind firms' decisions to make their products compatible or not. A key factor is the perception by firms that they can win a standards war in an unregulated setting and drive potential rivals out of the market. This may happen due to first-

\footnotetext{
${ }^{1}$ Veblen (1899) pioneered the study of interdependent demands in the form of fashion, fads and bandwagon effects and their novel implications of a macroeconomic nature (see also Leibenstein, 1950).

${ }^{2} \mathrm{~A}$ third, hybrid case, often prevails in practice: an industry may have two incompatible standards, each being adopted by a subset of the firms, in such a way that firms with the same standard have mutually compatible products. The Betamax-VHS standard war went through a phase of such coalitional rivalry.
} 
mover advantages (e.g., early entry), or to quality differences in the firms' products. Firm-specific networks may also emerge due to reluctance on the part of firms to adopt a rival's standard at the expense of their own, which may be due to fixed costs, hubris, or brand protection. Shapiro and Varian (1998) refer to single-network industries as ones where firms compete in the market, and to the case of firm-specific networks as representing attempts by some firms to compete for the market. ${ }^{3}$

There are also multiple reasons for a single network to emerge from a social welfare perspective, often owing to some form of government intervention. In his detailed study of the history and evolution of many network industries, Rohlfs (2003) argues forcefully that a single network is always preferable from a welfare perspective, and often also from the firms' standpoint, in particular when the viability of the industry itself is at stake. ${ }^{4}$ Two notable stylized facts about most, though not all, of these standards wars are worth recalling. They were relatively shortlived, typically lasting between a few years (e.g., the DVD war) to more than ten years (the VCR war). The second is that a standards war typically delays the overall development of the entire industry, negatively impacting both the supply and the demand sides (as was clearly seen e.g., in the DVD war). As will be seen below, the present study sheds quite some light of the latter stylized fact.

The literature on firm-specific networks includes quite a few studies on the evolution of such industries and their possible tipping towards a dominant standard. ${ }^{5}$ These studies do not focus on investigating the market performance of such industries with a view to shed light on their stylized facts, such as their tendency for a short-lived time span and the slow-down of their progress to a mature industry. To this end, a comparative perspective vis a vis single-network

\footnotetext{
${ }^{3}$ Among industries with firm-specific networks, some well known cases that made headlines due to a standards war include: high-definition optical discs for high-definition video and audio (with Blu-ray overtaking HD DVD); video cassette recorders (Sony's Beta format lost out to JVC's VHS format after a long battle); video games consoles (Nintendo secured a near-monopoly after driving Atari out of the market); personal computers (early on, IBM and Macintosh computers were not compatible); digital music systems such as digital compact cassette and mini disc; operating systems (Microsoft's DOS was chosen over Apple's), and bank ATMs. For more details, see Church and Gandal, 1992; Cusumano, Mylonadis and Rosenbloom, 1992; Katz and Shapiro, 1986, and Rohlfs, 2003).

${ }^{4}$ To be formally defined in the next section, the present notion of viability is meant to capture the idea that the industry will not uravel to the trivial equilibrium with zero output, due to the role of expectations in demand.

${ }^{5}$ Among others, see Grilo, Shy and Thisse (2001), Crémer, Rey and Tirole (2000), Resende (2008), Laussel and Resende (2014), Garcia and Vergari (2015), Markovich and Moenius (2009), and Laussel, Van Long and Resende (2015).
} 
industries beyond Katz and Shapiro (1985) seems natural. This paper is an attempt to fill this gap in the literature. Thus despite the oft-transient nature of the phase with firm-specific networks in an industry life-cycle, we believe it is important to provide a theoretical analysis of the relative performance of such markets. As a final word on motivation, firm-specific networks are likely to continue to emerge sporadically in new industries, despite their frequent tendency to be short-lived. A recent example is that Tesla has developed its own exclusive charging stations for its high-end electric vehicles. ${ }^{6}$ In this respect, it is worth adding that part of the more recent literature on network effects is in environmental economics, and largely postulates firm-specific networks (see Greaker and Midttømme, 2016 and Brécard, 2013). ${ }^{7}$

This paper focuses on a comparative study of market performance for industries with firmspecific networks and their counterparts with a single network. In other words, we investigate the effects of interconnection in network industries (Rohlfs, 2003). To do so, we first investigate the properties of firm-specific industries based on symmetric equilibria as a simplifying assumption for the transient phase of their life-cycle, as described earlier. Imposing a general structure on the model corresponding to the Cournot counterpart exhibiting strategic substitutes, we begin with a general existence result for symmetric rational-expectations equilibrium (as defined by Katz and Shapiro, 1985). ${ }^{8}$

Network industries can also be classified as to whether the product is a pure or a mixed network good. The former derive their value solely from network externalities (and have no intrinsic value in isolation), and include most telecom products. Mixed network goods instead possess both intrinsic and network value components, and include software and fashion goods. An important simplifying assumption in Katz and Shapiro (1985) is that these two components

\footnotetext{
${ }^{6}$ This emerging industry has indirect network effects defined as those that operate via the availability of complementary products, in this case charging stations and other specialized services.

${ }^{7}$ The rich literature on two-sided markets is also related, due to the presence of cross-network effects (e.g., Rochet and Tirole, 2006, Armstrong, 2006, and Jullien, 2011, among others). A recent strand of policy-focused literature argues that some of the industries viewed as two-sided markets (such as search engines) in fact reflect only one-sided network effects,(e.g., Luchetta, 2014 and Filistrucchi et. al., 2014). As such, these markets might thus better fit the present setting Indeed, the main point put forward in the latter pair of studies is that, while advertizers care about the number of users, the opposite is often not true. This would add a potentially long list of examples that partially fit the present setting, including search engines such as Google, and social media such as Facebook, etc...

${ }^{8}$ The assumptions on a standard Cournot model that make it a game of strategic substitutes are well-known and quite general: See Novshek (1985) and Amir (1996a). These are widely adopted in various studies in industrial organization that are based on general functional forms (see e.g., Vives, 1999).
} 
appear additively in a consumer's utility function, and are thus independent. One implication is that the lowest possible demand function, corresponding to an empty network, is positive. It follows that their results apply only to mixed network goods and preclude the viability issue. In contrast, as in AL (2011), we consider a general demand structure characterized by (i) strategic substitutes for the Cournot part of the model, (ii) a general structure of network effects that make demand less elastic, and (iii) the key advantage of nesting the important special case of pure network goods. For such goods, the problem of viability turns out to be of crucial importance: whether or not the launch of a new industry featuring a pure network good succeeds or fails depends critically on how expectations affect the set of possible inverse demand functions. Since our setting allows for pure network goods as a special case, we also provide an existence argument for non-trivial equilibria, i.e., ones with strictly positive output. This result is clearly needed since the trivial equilibrium is always present for a pure network good, as a sort of self-fulfilling expectation. As a result, the critical issue of viability then arises naturally, and is of substantial economic and policy interest, as shown by some of Rohlfs' (2003) case studies. Our study of this issue is based on the asymptotic properties of the usual expectations-augmented Cournot adjustment process. ${ }^{9}$ The existence of a non-trivial equilibrium ensures that the industry is viable or conditionally viable. ${ }^{10}$ As to the factors that have direct influence on viability, we focus on technological progress and exogenous entry. While the effect of the former is positive (as expected), an increase in the number of firms in the industry actually lowers its viability, which is less intuitive. In other words, for industries with firm-specific networks, monopoly leads to the highest prospects for viability! This is in sharp contrast to single-network industries wherein entry raises viability prospects (AL, 2011).

The central part of the paper conducts a comparison of overall market performance between the two types of network industries. First, on the critical issue of viability, our results constitute a crucial complement to those of AL (2011). Taken together they form a thorough vindication of the conclusions on viability reached by Rohlfs (2003) by introspection through his extensive case studies: as far as viability is concerned, the case of firm-specific networks is unambiguously inferior to the single-network case, except in the case of monopoly for which the two models fully coincide. ${ }^{11}$ Second, as regards the role of network structure in market performance, the

\footnotetext{
${ }^{9}$ Recall that in their seminal work, Katz and Shapiro (1985) restrict consideration to network industries that are always viable, and thus do not address the viability question. The same is true of the follow-up literature.

${ }^{10} \mathrm{As}$ in AL (2011), these notions are defined via the convergence of the said adjustment process to a non-zero equilibrium from any or from a sufficiently high, initial belief about the network size.

${ }^{11}$ Gans, King, and Wright (2005) provide evidence on the speed of adoption of communication technologies
} 
main finding is that, under our general assumptions, the single-network case offers superior market performance than the firm-specific network case in terms of equilibrium output, profit, and social welfare. On the other hand, we demonstrate via a robust example (with closed-form solutions) that these widely held views may well be reversed when the Cournot part of the model violates strategic substitutes, thus also establishing that our basic assumptions are critical for the general analysis. In addition, the comparison of consumer surplus requires a more restrictive condition on demand. In light of these general conclusions coupled with possible reversals, the theoretical investigation at hand appears needed as a way to gauge the well-foundedness of the conventional view, which was based on a number of observed cases and stylized facts but little formal analysis.

Recalling a key proviso of the Katz-Shapiro equilibrium concept - that demand is endogenous in both cases- the conclusions of the performance comparison directly imply that overall demand is lower in the case of firm-specific networks. We thus theoretically uncover another key stylized fact, namely that firm-specific networks tend to hamper demand and delay the development of the industry, as widely seen, e.g., in the DVD standards war. The idea is that consumers delay making a purchase, due to the fear that the network benefit would disappear if the selected product ended up losing out in the competition for the market. By positing rational expectations on firm-specific networks, the equilibrium concept captures the resulting consumers' lower willingness to pay. This prediction is another factor in favor of this equilibrium concept, the first being its suitability to capture the viability issue.

As to the organization of the paper, it proceeds in the chronology described in the summary of our results given above. The proofs are all gathered in the last section. As a final remark, several examples with closed-form solutions are provided throughout the paper as simple illustrations of key conclusions of interest in a manner accessible to all.

\section{Oligopoly with firm-specific networks}

\subsection{The model and the assumptions}

Here we describe the model as a static game of oligopolistic competition in an industry with a homogeneous good with positive network effects and complete inter-firm incompatibility. This is a market situation where the firms produce perfect substitutes and the consumers' willingness to with network effects, depending on compatibility (see also Liebowitz and Margolis, 1994). 
pay for a good is increasing in the number of agents that purchase the good from the same firm. In other words, the goods are not compatible across firms; rather every firm possesses its own network. This model is a generalization of the second model of oligopoly with network effects, the one with complete incompatibility, introduced by Katz and Shapiro (1985). In equilibrium, every firm maximizes its profit given the total output of the rival firms, with each firm's output matching its own expected network size. This corresponds to the so-called fulfilled expectations Cournot equilibrium (henceforth RECE), due to Katz and Shapiro (1985), and formally defined below.

Every firm in the market faces the inverse demand function $P(z, s)$, where $z$ denotes the total output in the market and $s$ the expected size of the firm's network. Each firm has its individual network with expected size $s$, which is not necessarily the same across firms (but will be at the symmetric equilibria that we consider). If every consumer purchases at most one unit of the good, $s$ accounts for the expected number of agents that will purchase the good from that same firm.

The firms face the same linear cost of production. ${ }^{12}$ Hence, for given $s$, firm $i$ chooses the output that maximizes its profit given by

$$
\pi(x, y, s)=x P(x+y, s)-c x
$$

where $c \geq 0$ is the unit cost, $x$ is the firm's output level and $y$ is the joint output of the other $(n-1)$ firms. The firm does not get to choose $s$; rather, this is an exogenous expectations variable for the firm, in that the firm does not have the power to influence consumers' expectations about its own network size (just as in Katz and Shapiro, 1985).

Then, the firm's best reaction correspondence is given by

$$
x(y, s)=\arg \max \{\pi(x, y, s): x \geq 0\} .
$$

Alternatively, one can think of firm $i$ as choosing total output $z=x+y$, which maximizes

$$
\tilde{\pi}(z, y, s)=(z-y) P(z, s)-c(z-y)
$$

with best-reaction correspondence

$$
z(y, s)=\arg \max \{\tilde{\pi}(z, y, s): z \geq y\},
$$

\footnotetext{
${ }^{12}$ Although our approach can easily handle a more general cost function, we abstract away from cost curvature effects, since we wish to stress that the departures from standard oligopoly results that we are about to establish are all due to demand-side network effects. This is in contrast to the results of Amir and Lambson (2000) where counterintuitive findings are due to increasing returns to scale in production.
} 
given a particular $y$ and $s$. Then, it should be the case that $z(y, s)=x(y, s)+y$.

The equilibrium concept for this model, due to Katz and Shapiro (1985), is called a rational expectations Cournot equilibrium (or RECE), defined as follows.

Definition 1 A RECE consists of vectors of outputs $\left(x_{1}^{*}, x_{2}^{*}, \ldots, x_{n}^{*}\right)$ and expected networks sizes $\left(s_{1}, s_{2}, \ldots, s_{n}\right)$ such that:

(1) $x_{i} \in \arg \max \left\{x P\left(x+\sum_{j \neq i} x_{j}^{*}, s_{i}\right)-c x: x \in[0, K]\right\}$, and

(2) $x_{i}^{*}=s_{i}, i=1,2, \ldots, n$.

Although widely accepted as an appropriate solution concept for industries with network effects, RECE is nevertheless still somewhat controversial. A discussion of its justification is now provided. This notion of equilibrium requires that both consumers and firms correctly predict the market outcome, so that their common beliefs are confirmed in equilibrium. While strategic in their choice of outputs in the usual Cournot sense, firms are "network-size taking" in their perceived inability to directly influence customers' expectations of market size. One plausible justification for this is that firms are unable to credibly commit to output levels that customers could observe and reliably use in formulating expectations about network size (Katz and Shapiro, 1985). Naturally, the plausibility of the RECE concept increases with the number of firms present in the market. ${ }^{13}$

The RECE concept has a dual nature: It consists of the conjunction of a standard Cournot equilibrium and a rational expectations requirement. (The latter is not related in any way to uncertainty but rather to the determination of the true final demand that will prevail in the economy.) The RECE concept pins down both firms' strategic behavior in the market and the coordination of expectations as to the right market size in a static model. ${ }^{14}$

An alternative solution concept has also been proposed for environments where firms possess the ability to make credible commitments to output levels: standard Cournot equilibrium with

\footnotetext{
${ }^{13} \mathrm{~A}$ well-known parallel is the fact that the price-taking assumption of perfect competition is more plausible in markets with many producers, and thus more diffuse competition.

${ }^{14}$ It is possible to think of RECE as a fully game-theoretic concept, but in the context of a two-stage game, as follows. In the first stage, a market maker (or a regulator) announces an expected network size $s$ per-firm. In the second stage, firms compete in Cournot fashion facing inverse demand $P(z, s)$. If the market maker's objective function is to minimize the gap between the announced per-firm network and its Cournot equilibrium output, then to any subgame-perfect equilibrium of this game corresponds a RECE of the Cournot market with network externalities, and vice-versa. This simple interpretation of the RECE solution also provides one natural approach for arriving at a RECE with the participation of a market maker, and in case of multiple equilibria, also for selecting a particular RECE. This construction is reminiscent of a Walrasian auctioneer in general equilibrium.
} 
inverse demand $P(x+y, x)$. A direct comparison between these two concepts appears in Katz and Shapiro (1985), who find that firms' market behavior is more aggressive, leading to a higher industry output than under the RECE concept, which is an intuitive outcome. Ultimately, the issue as to which of these concepts is more appropriate for network industries is an empirical matter, and the answer is likely to vary according to industry characteristics, in particular those relating to firms' ability to credibly commit (observability conditions, firm reputation, government participation, etc).

Importantly, replacing RECE with standard Cournot equilibrium for network industries would lead to the viability issue being the same as for regular industries. This is well-known not to be the case, as is confirmed by Rohlfs' detailed history of the viability of various network industries. Indeed, our results reinforce the conclusions of AL (2011) that the RECE concept captures the fact that the viability issue is often relevant for network industries. This is arguably the most convincing argument for the appropriateness of this concept for network industries.

The following basic assumptions will be in effect throughout the paper:

(A1) $P:[0, \infty)^{2} \rightarrow[0, \infty)$ is twice continuously differentiable, $P_{1}(z, s)<0$ and $P_{2}(z, s)>0$.

(A2) $x_{i} \leq K$, for each firm $i$.

(A3) $P(z, s)$ is a $\log$-concave function of $z$ for each $s$, i.e.,

$$
P(z, s) P_{11}(z, s)-P_{1}^{2}(z, s) \leq 0, \text { for all }(z, s) .
$$

The first assumption is standard in the literature. The usual law of demand is captured by $P_{1}(z, s)<0$. The part $P_{2}(z, s)>0$ reflects the positive network effects or demand-side economies of scale, i.e., consumers' willingness to pay increases when more people are expected to buy the good.

Recall that $(\mathrm{A} 1)$ implies that $\partial \tilde{\pi}(z, y, s) / \partial z \partial y \triangleq-P_{1}(z, s)>0$. Hence, every selection of the total output best-response correspondence, $z(y, s)$, is increasing in $y$ for each $s$. This property alone guarantees the existence of a symmetric Cournot equilibrium for each $s$, and the absence of asymmetric Cournot equilibria. For a detailed discussion, see Amir and Lambson (2000).

The capacity constraint assumption (A2) is only for the convenience of avoiding technical issues with unbounded outputs, with the magnitude of $K$ being immaterial to the results.

Assumption (A3) is well known to ensure that for fixed network size $s$, the Cournot oligopoly is a game of strategic substitutes, i.e., will have reaction curves that are decreasing in rivals' total 
output, in addition to implying a unique Cournot equilibrium for given $s$ (Amir, 1996a). ${ }^{15}$ The property of strategic substitutes is often associated with Cournot competition (Vives, 1999). To stress its broad level of generality for Cournot oligopoly, observe that it holds for any concave inverse demand (including the linear one), but also allows for inverse demands that are not too convex, the limit case being $e^{-z}$, which is clearly log-linear. On the other hand, Assumption (A3) is not universal since it is violated by very convex inverse demands such as the hyperbolic family, of the form $1 / z^{\alpha}, \alpha>0$. For a more detailed discussion, see Amir (1996a).

Nonetheless, Assumption (A3) is not crucial for the existence of RECE here; in fact, we could replace it with the log-supermodularity of demand and then use supermodularity arguments and Tarski's fixed point theorem (as in the approach taken in AL, 2011).

We impose no special restriction on the value of $P(z, 0)$. This characteristic of the inverse demand function allows the model to account for pure and mixed network goods. Pure network goods are those that do not have stand-alone value, i.e., $P(z, 0)=0$, meaning that if the expected size of the firm's network is zero, no consumer will value this good at all. On the other hand, $P(z, 0)>0$ reflects a mixed network good, one that the consumers value to some extent even if the expected size of the network is zero. As in AL (2011), both possibilities are allowed.

Throughout the paper, we shall find it instructive to compare the results pertaining to the present model to those of the related model with complete inter-firm compatibility (Katz and Shapiro, 1985, and AL, 2011). In so doing, we shall refer to the former model as oligopoly with firm-specific networks (or with complete incompatibility, or just incompatibility), and to the latter as oligopoly with a single-network (or with complete compatibility, or just compatibility). The analysis of the paper uses the basic results from the theory of supermodular games in ways that are similar to AL (2011). ${ }^{16}$

As to notation, the subindex $n$ is added to any variable to denote that the variable in question is in equilibrium. The subindex $i$ is usually dropped for simplicity since we focus on symmetric equilibria in this paper. We will also often refer to RECE simply as "equilibrium".

\footnotetext{
${ }^{15}$ It is also closely related to the more familiar condition of marginal revenue decreasing in rival's output, or $P_{1}(z, s)+z P_{11}(z, s) \leq 0$, used by Novshek (1985) and others.

${ }^{16}$ This class of games has been studied extensively and applied to oligopoly theory; see Milgrom and Roberts (1990), Topkis (1998), Vives (1990, 1999), Amir (1996a), and Amir and Lambson (2000). More recent applications include Barthel and Sabarwal (2019) and Cosandier, Garcia, and Knauff (2018).
} 


\section{$2.2 \quad$ Existence of symmetric equilibrium and viability}

This subsection considers the existence of RECE, or for short simply, equilibrium, as a result of some minimal structure. Under Assumptions (A1)-(A3), maintained throughout, we will show that at least one symmetric equilibrium exists. In this paper, we focus on the symmetric RECE since this part of the model itself is rich in interesting results that complement those of the single-network model and allow for an instructive comparison. ${ }^{17}$

Recall that for fixed $n$ and $s$, under Assumptions (A1)-(A3), the standard Cournot oligopoly with inverse demand $P(z, s)$ possesses a unique and symmetric Cournot equilibrium (Amir and Lambson, 2000). Denote the per-firm equilibrium output by the single-valued function $q_{n}(s)$. From part (2) of the definition of RECE, a per-firm output $x_{n}$ constitutes a (symmetric) RECE output if it confirms the expected level of per-firm sales (or network size) that generated it, i.e., if $x_{n} \doteq q_{n}(s)=s$. Thus, if we graph $q_{n}(s)$ as a function of $s$, the RECE outputs coincide with the points where the function $q_{n}(s)$ crosses the $45^{\circ}$ line. This idea will play a key role in much of the upcoming analysis.

The first result deals with existence of RECE (all the proofs are collected in the Appendix).

Theorem 1 Under Assumptions (A1)-(A3), for each $n \in N$,

(a) the function $q_{n}(s)$ is continuously differentiable, and

(b) the Cournot oligopoly with firm-specific networks has (at least) one symmetric RECE.

In industries with network effects, it is quite possible to face a situation where the only equilibrium is the trivial one, where all the firms choose to produce zero output. Such an industry is then said to be non-viable. If $P(x, 0)=0$, then when $s=0$, each firm will produce zero output, and the trivial equilibrium becomes self-fulfilling, i.e., $q_{n}(0)=0$.

The following simple but important observation characterizes the trivial equilibrium.

Lemma 1 The trivial outcome is a RECE if and only if $x P(x, 0) \leq c x$ for all $x \in[0, K]$. Hence, the trivial outcome is a RECE for $n$ firms if and only if it is a RECE for $(n+1)$ firms.

A useful direct consequence of Lemma 1 is now noted. It holds that if for some $n$ the trivial equilibrium is not an equilibrium for an $n$-firm industry (i.e., if $q_{n}(0)>0$ ), it will not be an equilibrium for the same industry with any number of firms.

\footnotetext{
${ }^{17}$ Asymmetric equilibria are quite different in nature, and appear more suitable for a dynamic analysis. Thus this is set aside for further research. Katz and Shapiro (1985) do consider asymmetric equilibria.
} 
Corollary 1 If $q_{n}(0)=0$ for some $n$, then we must have $q_{n}(0)=0$ for all $n$.

In light of Lemma 1, Theorem 1 is a priori of potentially limited interest, in that the equilibrium that is shown to exist in a non-constructive manner may well be the trivial one. A natural question then is, what conditions on the primitives ensure the existence of a non-trivial equilibrium, i.e., one with strictly positive industry output. Theorem 2 below answers this question. To provide some context, recall that an important simplifying assumption in Katz and Shapiro (1985) and much of the follow-up literature is that the inverse demand is additively separable in output and network effects. One implication is that the lowest possible demand function, corresponding to an empty network, is positive. Hence, their framework precludes trivial equilibria, and thus also the study of the viability problem (discussed in detail by Rohlfs, 2003).

Theorem 2 A non-trivial symmetric RECE exists if at least one of the following conditions holds:

(a) $q_{n}(0)>0$ for some $n$, i.e., zero is not a RECE for some $n$ (or $x P(x, 0)>c x$ for some $x \in(0, K])$;

(b) $q_{n}(0)=0$ and $(n+1) P_{1}(0,0)+P_{2}(0,0)>0$; or

(c) $(n+1) P_{1}(0,0)+P_{2}(0,0)<0$, and $P(z, s)+\frac{z}{n} P_{1}(z, s) \geq c$ for some $s \in(0, K]$ and all $z \leq n s$.

The result in Theorem 2 part (a) is immediate from Corollary 1 and Theorem 1, because we know that at least one symmetric equilibrium always exists.

The most useful condition for the existence of a non-trivial equilibrium is probably that given in part (b). As will become clear in the proofs, the role of the condition $(n+1) P_{1}(0,0)+P_{2}(0,0)>$ 0 is to lead to the key property $q_{n}^{\prime}(0)>1$, thereby ensuring that the map $q_{n}(s)$ starts above the $45^{\circ}$ at 0 and therefore that it possesses a strictly positive fixed point.

As to part $(\mathrm{c})$, the condition $(n+1) P_{1}(0,0)+P_{2}(0,0)<0$ implies that $q_{n}(s)$ starts below the $45^{\circ}$ at 0 , but the role of the second condition in part (c) is to guarantee that the graph of $q_{n}(s)$ lies above the $45^{\circ}$ for some $s>0$, and this in itself implies the existence of a strictly positive fixed point for $q_{n}(s)$, or a non-trivial RECE.

We now use the last result to provide a systematic study of industry viability.

\subsection{Viability of oligopoly with firm-specific networks}

In this subsection, we thoroughly investigate the scope for industry viability for oligopoly with firm-specific networks, in particular its dependence on market structure and on technological 
progress. A comparison with the case of a single network is given in the next section.

In order to formally define the notion of viability, we consider the dynamic process given by the following expectations/network size recursion, starting from any initial $s_{0} \geq 0,{ }^{18}$

$$
s_{t+1}=q_{n}\left(s_{t}\right), t=0,1, \ldots
$$

An industry is said to be uniformly viable, or just viable for short, if the process (1) converges to a strictly positive equilibrium, or fixed-point of $q_{n}(\cdot)$, from any initial network size $s_{0}>0$. An industry is said to be conditionally viable if the same convergence takes place from any sufficiently large initial point, i.e. for $s_{0} \geq \bar{s}$, for some $\bar{s}>0$. The minimal such $\bar{s}$ is called the critical mass. ${ }^{19}$

As such, both the notions of viability and conditional viability require the existence of a non-trivial equilibrium. An industry without such equilibrium (i.e. with $q_{n}(\cdot)<s, \forall s$ ) is called non-viable. From the results in the previous subsection, it follows that an industry is non-viable if and only if the trivial outcome is its unique RECE.

These definitions are adapted from AL (2011), with the important difference that the relevant dynamic process (1) used in the latter study is, in the present notation,

$$
s_{t+1}=n q_{n}\left(s_{t}\right), t=0,1, \ldots
$$

We shall also need to quantify the concept of industry viability. The viability of an industry with firm-specific networks is said to increase if the critical mass increases, with the convention that the the critical mass of a non-viable industry is set to 0 (else, it would not not exist according to the definition). Increases in viability will be identified with upward shifts of the mapping $q_{n}(\cdot)$ below.

It is important to observe that the issue of viability does not arise in the early work of Katz and Shapiro (1985), and in the follow-up literature, as consequence of the simplifying assumption of additively separable inverse demand, namely that $P(z, s)=p(z)+g(s)$ for some functions $p$ and $g$. Under this formulation, $P(z, 0)>0$, and the viability problem is identical to its counterpart for regular (non-network) industries. It would only arise as a result of low demand,

\footnotetext{
${ }^{18}$ This process is well-known in the literature and may be viewed as an adaptation of classical Cournot bestreply dynamics to a model with rational expectations of market size. In fact, one can note that (1) is to RECE what Cournot best-reply dynamics is to Cournot equilibrium.

${ }^{19}$ Thus the critical mass is the minimal initial network size that ensures convergence to a strictly positive equilibrium. Indeed, iterating the adjustment process starting from any $s_{0}<\bar{s}$ will converge to the trivial equilibrium, interpreted as the extinction of the industry.
} 
relative to production costs. As we shall see below, the viability problem for general network industries has a much wider scope, as indeed reflected in the case studies by Rohlfs (2003).

The condition in Theorem 2 part (b) sheds some light on the role of market structure in determining viability, in the form of an upper bound on the number of firms that yields viability.

Corollary 2 A sufficient condition for viability for oligopoly with firm-specific networks is

$$
n<\frac{P_{2}(0,0)}{-P_{1}(0,0)}-1
$$

It can be seen by inspection that this condition is restrictive for large values of $n$, and will tend to hold only for small values of $n$. In particular, for any given inverse demand function $P$, there will be some $\bar{n}$ such that (3) fails for $n \geq \bar{n}$ (though conditional viability may then still hold via part (c)).

This condition can be interpreted as requiring that network effects around the origin be sufficiently strong, in that $P_{2}(0,0)$ must be large enough for (3) to hold.

The following result on how market structure affects viability is a key conclusion of this paper.

Proposition 1 As $n$ increases, the viability of an industry with firm-specific networks decreases.

As is apparent from the proof of this result in the Appendix, the direct effect of an exogenous increase in the number of firms $n$ is to shift the function $q_{n}(\cdot)$ downward. This shift then leads to the critical mass (weakly) decreasing, and thus to declining industry viability.

This result holds the opposite of the analogous result in [AL, 2011, Theorem 7], which says that a higher number of firms always enhances viability in the case of a single-network. In light of the latter result, it certainly appears counter-intuitive in the present context that viability is maximal for a monopoly, out of all market structures. At the same time, the two results complement each other nicely in providing a more complete picture of the issue of viability with regard to its dependence on the network structure and the market structure of an industry. In addition, the two results are needed together to fully confirm the main conclusion emphasized by Rohlfs (2003), namely that interconnection, or the presence of a single network, is a key characteristic that explains successful take-offs and survival of several network industries. Rohlfs (2003) provides several examples in the form of mini case studies where failure to launch is attributed, partly or mostly, to the presence of firm-specific networks (e.g, the early fax machine, compact discs, etc.). 
As in AL (2011), the effect of exogenous technological progress on viability is positive, which is a highly intuitive fact (being similar to the previous one, the proof is omitted).

Proposition 2 As c decreases, the viability of an industry with firm-specific networks increases.

In terms of how this result works, the direct effect of an exogenous decrease in the unit cost is to shift the function $q_{n}(\cdot)$ upward. This shift then leads to the critical mass (weakly) decreasing (as a consequence of the Correspondence Principle, see Echenique, 2002), and thus to declining industry viability.

\section{Compatibility versus incompatibility}

In this section, we provide a thorough comparison of industry viability and market performance for the two types of oligopoly when the exogenously given number of firms is the same in both markets. The issues at hand are clearly of substantial theoretical and practical interest for our understanding of the effects of network structure on industry performance. As such, this is the most important section of this paper, in particular with regards to policy implications.

Henceforth, we introduce the following key assumption, in line with AL (2011).

(A4) $\Delta_{1}(z, s) \triangleq P(z, s) P_{12}(z, s)-P_{1}(z, s) P_{2}(z, s)>0$ for all $(z, s)$.

Assumption (A4) means that the inverse demand function is strictly log-supermodular in $(z, s)$, which implies that every selection of $z(y, s)$ is increasing in $s$, for every $y$. The latter result follows because (A4) guarantees that the alternative profit function $\log \tilde{\pi}(z, y, s)$ has strict increasing differences in $(z, s)$, see Topkis (1998). The key consequence for our analysis below is that $q_{n}(s)$ is increasing in $s$, for each $n$ (see below). Assumption (A4) is quite broadly satisfied since it only imposes a restriction on how negative $P_{12}(z, s)$ can be. As such, (A4) reflects the demand-side scale economies associated with network industries (see AL, 2011 for more discussion).

Before proceeding to the main results of this section, we first note the main implication of Assumption (A4), which will be useful in proving some of the main results.

Lemma 2 Under Assumptions (A1)-(A4), $q_{n}(s)$ is increasing in $s$.

We begin with a comparison of viability. 


\subsection{Compatibility and viability}

In this subsection, we compare the scope for industry viability for the two types of oligopoly, with compatible networks (as in AL, 2011) and with firm-specific networks (as in the present paper).

The comparison of the viability of the models is stated next.

Proposition 3 If an industry with incompatible networks is viable (conditionally viable) for $n$ firms, for some $n \geq 1$, then the same industry with compatible networks is viable (conditionally viable) for a monopolist, and thus for any number of firms.

The reverse of Proposition 3 clearly does not hold in general, the one exception being the special case of monopoly for which the two models are fully equivalent. With the benchmark of monopoly as the common starting point, as more firms enter the market, viability increases for the single-network model whereas it decreases for the firm-specific network model.

Let us revisit Example 1 in AL (2011) to illustrate Proposition 3.

Example 1. Consider the inverse demand function $P(z, s)=\exp \left(-\frac{2 z}{\exp (1-1 / s)}\right)$ and no production costs. With compatible networks, AL (2011) show that (i) for any given $s$, every firm has a dominant strategy given by $x(y, s)=(1 / 2) \exp (1-1 / s)$, which is independent of $y$, and (ii) the industry emerges if and only if there are two or more firms in the market. A monopoly would choose not to produce since it is not profitable to do so. In other words, the function $q_{1}(s)=(1 / 2) \exp (1-1 / s)$ has a unique fixed point at 0, while the function $\exp (1-1 / s)$ has 2 fixed points, namely 0 and 1 , with 1 being a tangency point.

However, with incompatible networks, this industry will not emerge for any number of firms. Since every firm has its own network and has a dominant strategy (independent of the other players' choices), every single firm would behave as a monopolist in the compatible networks world, and hence every potential firm will decide not to enter the market. Formally, this equilibrium is given by the fixed point of $q_{n}(s)=(1 / 2) \exp (1-1 / s)$, which is unique and equal to 0.

Importantly, the viability problem is independent of the number of firms for this particular example. Due to the dominant strategy property, as $n$ increases, $q_{n}(s)$ remains constant, and thus failure of viability does not get any worse.

In terms of policy implications, the results of this section provide an instructive complement to the viability results in the single-network model (AL, 2011). Upon examining the birth 
and development of many different network industries since their early days, Rohlfs (2003) concludes that the single most important determinant of whether a newly launched network industry will survive is what he calls "inter-connection", which is synonymous with complete compatibility in this paper. ${ }^{20}$ As a particular case study, he covers in detail the history of the fax industry, starting with a failed initial launch in the mid-19th century, a failure he unambiguously attributes to two reasons: firm-specific networks (no inter-connection), and a poor and overtly costly production technology. In covering future steps in the evolution of this industry, he concludes that the much later successful launch of the fax industry in the 1980's was mostly due to government-mandated compatibility, and in addition to improvements in production technology. The results of this section, taken in conjunction with those of AL (2011), provide a very neat theoretical under-pinning for Rohlfs' for this and other case studies and policy analysis. $^{21}$

A key implication of the above results is that, in industries where inter-connection is difficult or overly costly to achieve, ${ }^{22}$ on account of the important issue of viability, monopoly might be socially preferable to any other market structure. This applies in cases where monopoly is the only viable market structure, or in cases where it is the only conditionally viable market structure with a sufficiently small critical mass (defined above as the smallest value of $s_{0}$ for which the adjustment dynamics converges to a strictly positive RECE; see also AL, 2011). Interestingly, this provides a novel motivation for what might be termed natural monopoly, although the underlying reasons are altogether different from the production efficiency considerations that underpin the classical notion. Clearly, in case of industries with firm-specific networks that can be viable only as monopolies, the reference to natural monopoly is unambiguously justified.

\footnotetext{
${ }^{20} \mathrm{He}$ also discusses the importance of technological progress in the production of network goods over time, but the role of this factor is more intuitive, and in line with regular (non-network) industries. The role of exogenous technological progress is captured by Proposition 2.

${ }^{21}$ Gans, King, and Wright (2005) consider a long list of communication industries with network effects and offer a more nuanced picture with a case-by-case discussion of several issues of interest.

${ }^{22}$ Inter-connection may fail to be implemented because of a variety of reasons, including historical factors, inability of firms to compromise on adopting a rival's standard, high costs sunk into firms' current standards, perceived threat to firms' prestige in case of abandonment of one's standard, etc. A frequent reason is perception by an industry leader that competition with firm-specific networks will end up driving its rivals out of the market.
} 


\subsection{Comparison of market performance}

In this subsection, we conduct an equilibrium comparison of market variables such as output, prices, profits, and welfare. Importantly, since market demand is endogenous under the RECE concept, we also end up at the same time comparing the levels of demand that arise under the respective equilibria of the two cases. It is useful to point out that, in light of our viability results, the comparison with equal numbers of firms is not necessarily the most relevant. Indeed, viability in the case of firm-specific networks typically would not involve many firms, in fact most of the time just two, sometimes three. The opposite tends to hold for the single network case, at least from a normative perspective. In view of the multiplicity of RECE, the comparisons will refer tacitly to the largest and smallest equilibrium variables. In order to distinguish the equilibrium variables between the two models, we add a superscript $\mathrm{C}$ for the case with compatibility and I for incompatibility.

The main results are that, under respective sets of sufficient conditions, the industry will produce a larger output, larger profits, a larger consumer surplus, and a higher social welfare when the networks are compatible than when they are firm-specific. Nonetheless, while the sufficient conditions for the conventional wisdom that a single network should yield higher market performance are satisfied quite broadly, they are not universal. Indeed, except for social welfare, the comparison can go in either direction, as shown via a series of example at the end of this section.

The first main result of this section covers the comparison between the two different network oligopolies in terms of outputs and prices.

Proposition 4 Under Assumptions (A1)-(A4), at any regular equilibrium,

(a) $\bar{x}_{n}^{C} \geq \bar{x}_{n}^{I}$, and thus $\bar{z}_{n}^{C} \geq \bar{z}_{n}^{I}$.

(b) The (endogenous) inverse demand functions in Cases $C$ and I satisfy $P\left(\cdot, \bar{z}_{n}^{C}\right)>P\left(\cdot, \bar{x}_{n}^{I}\right)$.

(c) $P_{n}^{C}=P\left(n \bar{x}_{n}^{C}, n \bar{x}_{n}^{C}\right) \geq P_{n}^{I}=P\left(n \bar{x}_{n}^{I}, \bar{x}_{n}^{I}\right)$ if (with all the $P$ terms evaluated at $(n x, x)$ )

$$
\Delta_{4}(z) \triangleq-P_{1} P_{2}+z\left(P_{1} P_{12}-P_{2} P_{11}\right) \geq 0 .
$$

We now argue that Proposition 4(a) is overall quite intuitive and in line with the stylized facts about network industries. Consumers have a higher willingness to pay under a single, larger, network, so the latter leads to a much larger demand, which intuitively should call for higher output per firm and price at the same time. However, as it turns out, for price to be 
higher in Case C requires (4) as sufficient condition. While (4) is not needed for output to be higher in Case C, Assumption (A3) is critical, as is shown in Example 4 below.

Keeping in mind that demand is endogenous in the two models, part (b) is a direct corollary of part (a). The market demand is typically much higher under Case $\mathrm{C}$ than under Case I, since $P\left(\cdot, \bar{z}_{n}^{C}\right)=P\left(\cdot, n \bar{x}_{n}^{C}\right) \geq P\left(\cdot, n \bar{x}_{n}^{I}\right)>P\left(\cdot, \bar{x}_{n}^{I}\right)$, for $n \geq 2$. This theoretical outcome is fully consistent with the observed reluctance of consumers to make a purchase in several well-known cases involving a standards war between two major suppliers for fear that they might purchase the wrong standard (that will end up being discarded). Consumer delay and the concomitant demand reduction were often observed, and recently documented during the highly publicized war between the HD DVD disc and Blu-ray discs in 2006-08.

Unlike outputs, a clear-cut price comparison requires Condition (4), which is quite general. A sufficient condition for (4) is to have both $P_{21}<0$ and $P_{11}<0$, each of which is moderately general, or the combined condition that $P_{2}(z, x) / P_{1}(z, x)$ is increasing in $z$.

It is important to stress that although Condition (4) is quite general, it is not universal, and that in addition Assumption (A3) is critical for this Proposition (for both parts a and b). Indeed, an example is given below to show that the two conclusions of Proposition 4 (a) and (c) may be reversed with a hyperbolic type of inverse demand function.

The second result covers the comparison of profit, consumer surplus and social welfare.

Proposition 5 Under Assumptions (A1)-(A4), at any regular equilibrium,

(a) $\pi_{n}^{C} \geq \pi_{n}^{I}$ if (with all the $P$ terms evaluated at $(n x, x)$ )

$$
\Delta_{5}(z) \triangleq-P_{1}\left(2 P_{2}+x P_{12}\right)+z\left(P_{1} P_{12}-P_{2} P_{11}\right) \geq 0 .
$$

(b) $C S_{n}^{C} \geq C S_{n}^{I}$ if $P_{12}(z, s) \leq 0$.

(c) $W_{n}^{C} \geq W_{n}^{I}$.

For the profit comparison, it is of interest to observe that Condition (5) is less restrictive than Condition (4), in light of Assumption (A4). Thus an intuitive price comparison across Cases $\mathrm{C}$ and $\mathrm{I}$ is sufficient for an intuitive profit comparison.

As for consumer surplus, the sufficient condition $P_{12}(z, s) \leq 0$ is more restrictive than the others, though clearly compatible with Assumption (A4). Example 5 below shows that the consumer surplus comparison may well go the other way without this assumption.

For the welfare comparison, the result is part of the conventional wisdom on the benefits of a single network. All together then, society is always better off under complete compatibility, 
but we cannot conclude in as much generality that both the firms and the consumers will always prefer a single-network industry. The result is also a vindication of the recommendation by policy experts for social planners to favor inter-connection, e.g., Rohlfs (2003). Interestingly, this is the only result that fully confirms the conventional wisdom (without additional assumptions).

From the proofs of Propositions 4(c) and (5), one can see that the price and profit comparison will be reversed if Conditions (4) and (5) are reversed, respectively. This is highly counterintuitive, and runs counter to the conventional view about the comparison at hand. On the other hand, it must also be pointed out that the reverse of Conditions (5) reflects little generality.

To garner further insight, both quantitative and qualitative, into various aspects of the comparison between the two cases, we now provide three different examples with simple inverse demand functions. The first example is based on a linear demand for a mixed network good with additive network effect, and thus builds directly on the formulation in Katz and Shapiro (1985).

Example 2. Consider an oligopoly with inverse demand function $P(z, s)=\max \{a+s-z, 0\}$, $0 \leq a \leq K$ and $c=0$.

The first order condition reduces to $a+s-2 x-y=0$, which yields ${ }^{23}$

$$
q_{n}(s)=\frac{a+s}{n+1}, \bar{z}_{n}^{I}=a, \bar{z}_{n}^{C}=n a, P_{n}^{I}=\frac{a}{n}, \text { and } P_{n}^{C}=a .
$$

Therefore, the (endogenous) inverse demand functions in Cases I and C are

$$
P^{I}\left(z, \bar{x}_{n}^{I}\right)=(1+1 / n) a-z \text { and } P^{C}\left(z, \bar{z}_{n}^{C}\right)=(1+n) a-z .
$$

Hence, the gap in linear demand intercepts between Cases $\mathrm{C}$ and I increases with $n$; e.g., we have $3 a$ versus $1.5 a$ for $n=2$, and $5 a$ versus $1.25 a$ for $n=4$.

This example shows that equilibrium price, industry output and the level of demand are much higher in the compatible world. These differences are to be (qualitatively) expected since the network is larger and consumers' willingness to pay increases with the size of the network.

Example 3. Let $P(z, s)=s e^{-z}$ and $c=0$. A firm's profit function is $\pi(x, y, s)=x s e^{-(x+y)}$. Solving the first-order condition $s e^{-(x+y)}(1-x)=0$ yields the unique RECE with multiple networks

$$
x_{n}^{I}=1, \quad z_{n}^{I}=n, P_{n}^{I}=\pi_{n}^{I}=e^{-n}, C S_{n}^{I}=1-(n+1) e^{-n}, \text { and } W_{n}^{I}=1-e^{-n} .
$$

\footnotetext{
${ }^{23}$ Here, $\bar{z}_{n}^{I}$ solves $q_{n}(s)=\frac{a+s}{n+1}=s$, while $\bar{z}_{n}^{C}$ solves $n q_{n}(s)=\frac{n(a+s)}{n+1}=s$.
} 
On the other hand, with a single network, the symmetric RECE is

$$
x_{n}^{C}=1, \quad z_{n}^{C}=n, P_{n}^{C}=\pi_{n}^{C}=n e^{-n}, C S_{n}^{C}=n\left[1-(n+1) e^{-n}\right], \text { and } W_{n}^{C}=n\left[1-e^{-n}\right] .
$$

The (endogenous) inverse demand functions in Cases I and C are

$$
P^{I}\left(z, x_{n}^{I}\right)=e^{-z} \text { and } P^{C}\left(z, z_{n}^{C}\right)=n e^{-z}
$$

Hence, the gap in the size of demand between Cases $\mathrm{C}$ and I increases linearly with $n$; e.g., we have $2 e^{-z}$ versus $e^{-z}$ for $n=2$, and $4 e^{-z}$ versus $e^{-z}$ for $n=4$.

This example also shows that equilibrium per-firm outputs can be the same for the two types of oligopoly (and be independent of the number of firms); this is thus a limit case of Proposition 4(a). Nonetheless, the resulting price, the level of demand, per-firm profit and welfare are higher in the compatible world, with the respective gaps growing linearly with $n$.

Finally, we note that Cases $\mathrm{C}$ and I also feature conflicting industry profit comparisons for monopoly and duopoly, as

$$
2 \pi_{2}^{C}=0.5413 \geq \pi_{1}^{C}=\pi_{1}^{I}=0.3679 \geq 2 \pi_{2}^{I}=0.2707
$$

This confirms the co-opetitive nature of the RECE concept for single-network industries and the lack thereof for industries with firm-specific networks.

We now present a key example that sheds light on the main results of the paper (in particular on the comparison between Cases I and C), and also on the role of Assumption (A3) in the overall analysis. In terms of the comparative performance of the two cases, this example shows the rather counter-intuitive fact that price and profit may be higher in Case I. As to Assumption (A3), Example 4 shows that without it, per-firm output need not be monotonic in $n$.

Example 4. Let $P(z, s)=s+100 / z^{2}$ and $c=10, s \leq 10$. A firm's profit function is then given by $\pi(x, y, s)=(s-10) x+\frac{100 x}{(x+y)^{2}}$.

Since $P$ is a globally log-convex function in $z$, it clearly violates Assumption (A3). Yet such iso-elastic demands have often been used in industrial organization.

The FOC, $\partial \pi(x, y, s) / \partial x=0$, reduces to

$$
100(y-x)=(10-s)(x+y)^{3} .
$$

To solve for the symmetric Cournot equilibrium given $s$, we first note that for $n=1$ and $n=2$, the only Cournot equilibrium for $s \leq 10$ is to produce zero output. Hence, we have the trivial 
outcome as unique RECE for both oligopolies when $n \leq 2$, i.e., $x_{1}=x_{2}=0$, and thus a non-viable industry.

On the other hand, when $n \geq 3$, we solve (6) to obtain

$$
q_{n}(s)=\sqrt{\frac{100(n-2)}{(10-s) n^{3}}} .
$$

Restricting attention to $n=3$ and $n=4$ for brevity, for Case I, solving $q_{n}(s)=s$, the unique RECE has per-firm output, industry output, price and per-firm profit respectively given by

$$
\begin{aligned}
& x_{1}^{I}=0, x_{2}^{I}=0, x_{3}^{I}=0.629, x_{4}^{I}=0.576 . \\
& P_{1}^{I}=\infty, P_{2}^{I}=\infty, P_{3}^{I}=28.743, P_{4}^{I}=19.424 . \\
& \pi_{1}^{I}=\infty, \pi_{2}^{I}=\infty, \pi_{3}^{I}=11.783, \pi_{4}^{I}=5.427 .
\end{aligned}
$$

For Case C, solving $n q_{n}(s)=s$, the unique RECE has per-firm output, industry output, price and per-firm profit respectively given by

$$
\begin{aligned}
& x_{1}^{C}=0, x_{2}^{C}=0, x_{3}^{C}=0.682, x_{4}^{C}=0.65 . \\
& P_{1}^{C}=\infty, P_{2}^{C}=\infty, P_{3}^{C}=25.905, P_{4}^{C}=17.40 . \\
& \pi_{1}^{C}=\infty, \pi_{2}^{C}=\infty, \pi_{3}^{C}=10.854, \pi_{4}^{C}=4.81 .
\end{aligned}
$$

Thus, for all $n>2$, the industry is viable. This does not violate our viability results, since the latter rely on Assumption (A3), which is violated here.

As $n$ increases, we have the following effects of interest:

(i) Cases I and C have the same RECE for the duopoly case (in addition to the monopoly case).

(ii) For both Cases I and C, price and per-firm profit decrease globally in $n$.

(iii) Both price and per-firm profit are higher in Case I than in Case C. These two reversals indicate that the conditions in Propositions 4-5 are needed for the results that price and perfirm profit are higher in Case C.

(iv) Despite the price comparison reversal, the endogenous inverse demands in Cases I and C still satisfy Proposition 4 since

$$
\begin{aligned}
& P^{I}\left(z, x_{3}^{I}\right)=0.629+100 / z^{2}<P^{C}\left(z, z_{3}^{C}\right)=2.046+100 / z^{2} \text { for } n=3 \\
& P^{I}\left(z, x_{4}^{I}\right)=0.576+100 / z^{2}<P^{C}\left(z, z_{4}^{C}\right)=2.6+100 / z^{2} \text { for } n=4 .
\end{aligned}
$$

Although the evaluation of consumer surplus for this demand function is problematic (as it is infinite), we can compare Cases C and I by truncating away consumer surplus up to some 
small output. Doing so yields a confirmation of Proposition 5(b), as expected since $P_{12}=0$ here.

Importantly, via point (iii), this example provides an argument against the conventional wisdom about the overall superiority of having an industry-wide network (as argued persuasively in Shapiro and Varian, 1998 and Rohlfs, 2003). Thus for this widely held view about the comparison between the two cases to hold as far as profitability is concerned, the sufficient conditions given in Propositions 4 and 5 are needed. While these conditions are quite general, they are not universally satisfied, as highlighted by the hyperbolic demand used in Example 4 being one of the most widely used specifications in industrial organization. ${ }^{24}$

Finally, notice that $x_{n}^{I}$ increases for $n \leq 3$ and decreases for $n \geq 3$. Due to this inverse demand violating Assumption (A3), per-firm output $x_{n}^{I}$ is not globally decreasing in $n$. This outcome takes place just in the same way as in regular Cournot oligopoly. In order to avoid adding another layer of complexity to an already rich set of possible outcomes, we have decided to impose (A3), in line with much of Cournot oligopoly theory.

A final example is provided to illustrate that consumer surplus can be larger under multiple networks (when $P_{12}$ is not $\leq 0$ ), and have opposite comparative statics across the two cases, we simply extend Example 3 in AL (2011) as follows.

Example 5. Let $P(z, s)=\max \left\{a-z / s^{3}, 0\right\}$, with $a \geq n / K^{2}$ and $K>1$, and assume that firms face zero production costs. The reaction function of a firm is given by

$$
x(y, s)= \begin{cases}\max \left\{\left(a s^{3}-y\right) / 2,0\right\}, & \text { if }\left(a s^{3}-y\right) / 2<K, \\ K & \text { if }\left(a s^{3}-y\right) / 2 \geq K .\end{cases}
$$

With a single network, the RECE industry output set is $z_{n}^{C}=\{0, \sqrt{(n+1) / n a}, n K\}$. For the highest equilibrium $\bar{z}_{n}^{C}=n K$, consumer surplus is $C S_{n}^{C}=1 /(2 n K)$, which is decreasing in $n$.

With incompatible networks, the RECE industry output set is given by $z_{n}^{I}=\{0, n \sqrt{(n+1) / a}, n K\}$. Here the middle RECE is unstable and the highest one $\bar{z}_{n}^{I}=n K$ is stable. Taking the latter, we have $C S_{n}^{I}=n^{2} /(2 K)$, which is increasing in $n$, in contrast to the single-network case.

In addition,

$$
P_{n}^{C}=a-1 /(n K)^{2} \geq P_{n}^{I}=a-n / K^{2} \text { and } \pi_{n}^{C}=K\left(a-1 /(n K)^{2}\right) \geq K\left(a-n / K^{2}\right)=\pi_{n}^{I} .
$$

\footnotetext{
${ }^{24}$ While this demand function leads to a Cournot game that is not of strategic substitutes, other examples may be constructed to show that Proposition 4(c) may fail when Condition (4) alone is violated. A similar remark applies to Condition (5).
} 
Importantly, for this specification, consumer surplus under RECE is higher under incompatibility than under compatibility, with the gap $C S_{n}^{I}-C S_{n}^{C}$ increasing at the rate $n^{3}$ ! This is clearly consistent with Proposition 5 since $P_{12}>0$ here.

Despite the reversal of the consumer surplus comparison w.r.t. Proposition 5, we recover the social welfare comparison

$$
W_{n}^{C}=a n K-1 /(2 n K) \geq W_{n}^{I}=a n K-n^{2} /(2 K) .
$$

Finally, the endogenous inverse demands are, for Cases C and I respectively,

$$
P^{C}\left(z, \bar{z}_{n}^{C}\right)=a-z /(n K)^{3} \text { and } P^{I}\left(z, \bar{x}_{n}^{I}\right)=a-z / K^{3} .
$$

While these have the same intercepts, demand elasticity is far greater for Case I, with the gap increasing in $n$.

These results correspond to what Propositions 4 and 5 predict. Nonetheless, this example shows that the unconventional view that multiple networks can yield higher consumer surplus than a single network can prevail under a relatively robust specification of demand.

In conclusion, these examples provide clear illustrations that Propositions 4 and 5, which form the conventional view, do not hold under near-universal conditions, and that the opposite counter-intuitive outcomes may arise in robust ways, though not via a very general class of primitives. At the same time, these examples also partially reinforce the conventional view by providing an insightful quantitative dimension to the comparison, for instance in showing that endogenous demand may be substantially lower in the firm-specific case, even for the most relevant case of duopoly.

We close with an important note on another important implication of the RECE concept. Remark. As reported in AL (2011), the RECE concept for industries with network effects amounts to a nice illustration of the notion of co-opetition in the single-network case (e.g., Brandenburger and Nalebuff, 1996). Indeed, the concept treats firms as partners in jointly building a common network, but at the same time as Cournot-style rivals in serving that shared network and competing for its consumers. In contrast, the present results, in particular those on industry viability, indicate that the RECE concept here boils down to a notion of rivalry (with a key role for expectations). 


\section{Conclusion}

This paper has provided a thorough study of symmetric oligopolies with firm-specific network effects, in a comparative perspective with the case of single-network industries. Although the fact that the former type of industries are typically short-lived is broadly accepted as a stylized fact (Shapiro and Varian, 1998, and Rohlfs, 2003), a full theoretical understanding of the underlying reasons and of their overall performance is lacking in this literature.

Since the setting nests pure network goods (with trivial equilibria) as a special case, one needs to go beyond a fixed-point argument and provide a separate existence argument for nontrivial equilibria, building on the approach of AL (2011). This allows us to tackle the central issue of industry viability for new network industries, which is intimately tied to the role expectations play in such industries. The main result is that an increase in the number of firms operating in the industry actually lowers its viability. Therefore, monopoly leads to the highest prospects for viability, in sharp contrast to the case of single-network industries (AL, 2011). These two opposite results provide a complete theoretical foundation for the key conclusions on viability reached by Rohlfs (2003) through his multiple case studies: firm-specific networks lead to unambiguously inferior market performance relative to the single-network case, except in the case of monopoly for which the two models coincide. ${ }^{25}$ Our conclusions on viability, along with those of AL (2011), confirm the importance of viability for network industries, and thus provide an ex post justification for the concept of RECE as being appropriate for such industries.

A central issue the paper addresses is the comparison of market performance (beyond viability) between the two types of network industries. The main results again confirm that a single-network leads to unambiguously higher industry output and social welfare than firmspecific networks. With respective extra general conditions, the same conclusion extends to industry price and profits. On the other hand, a clear-cut comparison of consumer surplus requires a more restrictive assumption. In conclusion, although the conventional view about the superiority of single-network industries, articulated in Shapiro and Varian (1998) and Rohlfs (2003) without a proper theoretical foundation, is largely confirmed by the present analysis, some not insignificant qualifications are needed.

In terms of policy prescriptions, the main conclusion, derived from the combination of our

\footnotetext{
${ }^{25}$ We remind the reader that the issue of industry viability had not received any theoretical treatment in the extensive literature on network effects before AL (2011) for single-network industries, despite its prominence in the policy debates on network industries (Rohlfs, 2003, Shapiro and Varian, 1998, and Shy, 2001).
} 
results and those of AL (2011), is that Rohlfs' call for government-mandated interconnection as a blanket policy tool is clearly generally justified, both on grounds of enhanced prospects for viability for new network industries, and of superior social welfare for more mature industries. ${ }^{26}$ On the other hand, since the private incentives for inter-connection are less universally justified by the present analysis than the social incentives, absent any regulation, one should perhaps not be too surprised to occasionally observe firm-specific networks emerging in some industries (e.g., Tesla stations).

Last but not least, the present analysis provides further vindication for Katz and Shapiro's RECE as being an appropriate solution concept for static models of network industries. Both the viability results and the lower endogenous demand under firm-specific networks can be attributed in part to this concept. Indeed, under the alternative concept of standard Cournot equilibrium (as in the Appendix of Katz and Shapiro, 1985), possible non-viability and a tendency for low (endogenous) demand would not emerge as natural implications of the model.

As to related future work of interest, one natural model is to postulate just two standards or networks, with each being adopted by a number of competitors, and where the adoption decision is endogenous. This is a realistic model, and one that lies in an intermediate position between the two polar cases investigated so far and contrasted in the present paper. Another issue of obvious interest is to investigate in a dynamic setting the role of product differentiation in resolving standards wars in a favor of a winning firm in the underlying competition for the market.

\section{Appendix}

This appendix contains the proofs of all the results in this paper.

\section{Proof of Theorem 1}

(a) Let the expected size of the network be $s$ for each firm. From Amir and Lambson (2000), we know that, due to (A3), a unique and symmetric Cournot equilibrium exists for all $n$ and $s$. Let the corresponding per-firm equilibrium output be $q_{n}(s)$. By the upper hemi-continuity of the equilibrium correspondence for strategic games (e.g., Fudenberg and Tirole, 1991), $q_{n}(s)$ is upper hemi-continuous as a correspondence. Since it is also single-valued, it must be a continuous

\footnotetext{
${ }^{26}$ Gans, King and Wright (2005) offer a less unambiguous view on the problem of interconnection and of the role of government in some industries (see also Shapiro and Varian, 1998).
} 
function. Finally, by the (smooth) Implicit Function Theorem and the fact that $P$ is $C^{2}, q_{n}(s)$ is $C^{1}$ in $s$.

(b) Since the set of RECE coincides with the set of fixed points of $q_{n}(s)$, the existence of a RECE follows directly from Brouwer's fixed point theorem applied to the function $q_{n}(s)$, which is defined from $[0, K]$ to itself.

Proof of Lemma 1 By definition, an individual (and hence, industry) output of 0 is a symmetric RECE if $0 \in x(0,0)$. This holds if and only if $\pi(0,0,0) \geq \pi(x, 0,0) \forall x \in[0, K]$, i.e., $0 \geq x P(x, 0)-c x$ for all $x \in[0, K]$. Moreover, $q_{n}(0)=0$ if and only if $\pi(0,0,0) \geq \pi(x, 0,0)$ for all $x \in[0, K]$ if and only if $q_{n+1}(0)=0$.

The following lemmas will be useful to prove Theorem 2 .

Lemma 3 The function $q_{n}(s)$ is differentiable in $s$, and, if $q_{n}(s) \in(0, K)$ for $s>0$, one has

$$
\frac{\partial q_{n}(s)}{\partial s}=-\frac{P_{2}\left(n q_{n}(s), s\right)+q_{n} P_{12}\left(n q_{n}(s), s\right)}{(n+1) P_{1}\left(n q_{n}(s), s\right)+n q_{n} P_{11}\left(n q_{n}(s), s\right)} .
$$

In particular, if $q_{n}(0)=0$,

$$
\frac{\partial q_{n}(0)}{\partial s}=-\frac{P_{2}(0,0)}{(n+1) P_{1}(0,0)}
$$

Proof of Lemma 3 If $q_{n}(s)$ is interior, it satisfies the first order condition

$$
P\left(n q_{n}(s), s\right)+q_{n}(s) P_{1}\left(n q_{n}(s), s\right)-c=0 .
$$

Since $q_{n}(s)$ is $C^{1}$, one can differentiate both sides of equation (9) with respect to $s$. Reordering terms yields (7). Evaluating at $s=0$ and $q_{n}(0)=0$ yields $(8)$.

Let $\Pi(z, s) \triangleq \frac{n-1}{n}\left[\int_{0}^{z} P(t, s) d t-c z\right]+\frac{1}{n}[z P(z, s)-c z]$, a weighted average of welfare and industry profits when $s$ is the same for all firms. Similar to AL (2011), we have the following result relating, for given $s$, argmax's of $\Pi(z, s)$ and symmetric Cournot equilibria.

Lemma 4 If $z^{*} \in \arg \max \{\Pi(z, s), 0 \leq z \leq n K\}$, then, $x^{*} \equiv \frac{z^{*}}{n} \in q_{n}(s)$, for all $s \in[0, K]$. 
Proof of Lemma 4 Since the cost function is linear, it is convex. By AL (2011), Lemma 14, for any $n \in N$ and $s \in[0, K]$, if $z^{*} \in \arg \max \{\Pi(z, s), 0 \leq z \leq n K\}$, then, $z^{*} \in Q_{n}(s)$, where $Q_{n}(s)$ is the total output equilibrium correspondence for a given $s$. Then, by symmetry, $z^{*} \in Q_{n}(s)$ implies that $x^{*} \equiv \frac{z^{*}}{n} \in q_{n}(s)$.

\section{Proof of Theorem 2}

(a) If the trivial outcome is not part of the equilibrium set, Theorem 1 guarantees there is a symmetric RECE with strictly positive individual output.

(b) Parts (b) and (c) use the following argument. By the proof of Theorem 1, $q_{n}(s)$ is $C^{1}$ and maps $[0, \mathrm{~K}]$ into itself. In addition, suppose that there exists $s^{\prime} \in(0, K)$ such that $q_{n}\left(s^{\prime}\right)>s^{\prime}$, then, by Brouwer's fixed point theorem, it exists at least one fixed point, say $s^{\prime \prime}$, such that $s^{\prime \prime}>s^{\prime}$ and hence, $s^{\prime \prime}>0$, i.e., there exists a non-trivial symmetric RECE, $s^{\prime \prime}$. Therefore, we only need to show that such $s^{\prime}$ exists; to this end, it suffices to have $q_{n}^{\prime}(0)>1$, since it implies that there is a small $\epsilon>0$ for which $q_{n}(\epsilon)>\epsilon$. By hypothesis, $q_{n}(0)=0$ and by Lemma 3, $q_{n}^{\prime}(0)>1$ if $(n+1) P_{1}(0,0)+P_{2}(0,0)>0$, which proves our result.

(c) The third condition in this part implies that $\Pi_{1}(z, s) \geq 0$ for some $s \in(0, K]$ and for all $z \leq n s$, i.e., there exist $s \in(0, K]$ and $z^{\prime} \geq n s$ such that $\Pi\left(z^{\prime}, s\right) \geq \Pi(z, s)$ for all $z \leq n s$. Hence, the largest argmax of $\Pi(z, s)$, say $z^{*}$, must be greater than or equal to $n s$, i.e., $z^{*} \geq n s$ and $z^{*} / n \geq s$. By Lemma $4, z^{*} / n \in q_{n}(s)$ so there is an $s \in(0, K]$ such that an element of $q_{n}(s)$ is greater or equal than $s$. By the argument in part (b), it follows that a non-trivial symmetric equilibrium exists for $n$ firms.

Proof of Proposition 1 From Amir and Lambson (2000), Theorem 2.3, $q_{n}(s)$ is decreasing in $n$ for each fixed $s$ when $P$ is log-concave (this is just the condition for the regular Cournot game to be of strategic substitutes, for each fixed $s$ ). Consequently, the viability of the industry decreases in $n$ (since the critical mass increases).

Proof of Lemma 2 By Lemma 1 in AL (2011), and (A1)-(A4), every selection of the bestresponse correspondence $z(y, s)$ strictly increases in both $y$ and $s$ (this follows from a strengthening of Topkis's Theorem, see Amir (1996b) or Topkis, 1998, p.79). Then, the correspondence

$$
\begin{gathered}
B_{s}:[0,(n-1) K] \rightarrow 2^{[0,(n-1) K]}, \\
y \rightarrow \frac{n-1}{n} z(y, s)
\end{gathered}
$$


has a unique fixed point, which corresponds to the symmetric Cournot equilibrium (Amir and Lambson, 2000). By Milgrom and Roberts (1990), such fixed point, say $y_{n}(s)$, increases in $s$. Hence, by symmetry and $z(y, s)$ increasing in $s$, the function (by Proof of Theorem 1) $q_{n}:[0, K] \longrightarrow[0, K], q_{n}(s)=y_{n}(s) /(n-1)$, is increasing in $s$.

Proof of Proposition 3 By Proposition 1, if an industry with $n$ incompatible networks is viable, the industry with one incompatible network is too. In other words, $\bar{q}_{1}(s)$ has a fixed point different than zero which is also a non-trivial RECE for the monopolist with complete compatibility. Hence, the viability of the $n$-oligopoly with incompatible networks implies the viability of a monopolist in the single-network model. By AL (2011) Theorem 7, the viability of the industry with complete compatibility increases in $n$, which completes our proof.

\section{Proof of Proposition 4}

(a) The (largest) RECE of the oligopoly with incompatible networks is the (largest) fixed point of $\bar{q}_{n}(s)$, say $\bar{q}_{n}\left(s^{\prime}\right)=s^{\prime}$. Hence, $\bar{x}_{n}^{I}=s^{\prime}$.

On the other hand, the (largest) RECE of the oligopoly with a single-network maybe seen as the (largest) intersection point of $\bar{q}_{n}(s)$ with the line (through the origin) $s / n$, say $\bar{q}_{n}\left(s^{\prime \prime}\right)=s^{\prime \prime} / n$. Hence, $\bar{x}_{n}^{C}=\bar{q}_{n}\left(s^{\prime \prime}\right)$.

Since $\bar{q}_{n}(s)$ is increasing in $s$, it is easy to see that $\bar{x}_{n}^{C}=\bar{q}_{n}\left(s^{\prime \prime}\right)=s^{\prime \prime} / n \geq \bar{x}_{n}^{I}=\bar{q}_{n}\left(s^{\prime}\right)=s^{\prime}$.

It follows that industry output goes the same way, i.e., $\bar{z}_{n}^{C}=n \bar{x}_{n}^{C} \geq n \bar{x}_{n}^{I}=\bar{z}_{n}^{I}$.

(b) The endogenous inverse demand functions in Cases C and I are respectively $P\left(\cdot, n \bar{x}_{n}^{C}\right)$ and $P\left(\cdot, \bar{x}_{n}^{I}\right)$. The conclusion follows from part (a).

(c) For this proof and the proof of Proposition 5(a), we introduce an auxiliary parametrized Cournot oligopoly with an exogenous demand shifter $\alpha$. Thus we consider the profit function

$$
\Pi(x, \alpha)=x[P(x+y, \alpha)-c]
$$

and re-frame the questions as ones of comparative statics with respect to $\alpha$ in this Cournot game.

Now, to show that $P_{n}^{C}=P\left(n \bar{x}_{n}^{C}, n \bar{x}_{n}^{C}\right) \geq P_{n}^{I}=P\left(n \bar{x}_{n}^{I}, \bar{x}_{n}^{I}\right)$ we show that the Cournot equilibrium price in (10), call it $p(\alpha)$, is increasing in $\alpha$, under condition (4). This clearly implies our desired conclusion here, i.e., $P_{n}^{C}=p\left(n \bar{x}_{n}^{C}\right) \geq p\left(\bar{x}_{n}^{I}\right) \geq P_{n}^{I}$, in light of part (a).

The first order condition for a Cournot equilibrium in (10) may be rewritten as (with $z(\alpha)$ 
as equilibrium total output)

$$
n P(z(\alpha), \alpha)+z(\alpha) P_{1}(z(\alpha), \alpha)-n c=0 .
$$

Since there is a unique Cournot equilibrium under our assumptions, we can differentiate with respect to $\alpha$ throughout (11) and collect terms to obtain

$$
z^{\prime}(\alpha)=-\frac{n P_{2}(z(\alpha), \alpha)+z P_{12}(z(\alpha), \alpha)}{(n+1) P_{1}(z(\alpha), \alpha)+z P_{11}(z(\alpha), \alpha)} .
$$

Since $p(\alpha)=P(z(\alpha), \alpha)$, we have $p^{\prime}(\alpha)=P_{1}(z(\alpha), \alpha) z^{\prime}(\alpha)+P_{2}(z(\alpha), \alpha)$. Substituting (12) yields upon collection of terms that (with all $P$ terms evaluated at $(z(\alpha), \alpha)$ )

$$
p^{\prime}(\alpha)=-\frac{-P_{1} P_{2}+z\left(P_{1} P_{12}-P_{2} P_{11}\right)}{(n+1) P_{1}+z P_{11}}=-\frac{\Delta_{4}}{(n+1) P_{1}+z P_{11}} .
$$

The denominator $(n+1) P_{1}+z P_{11}<0$ by the stability (in the sense of best reply Cournot dynamics) of the unique Cournot equilibrium here; therefore $p^{\prime}(\alpha)$ has the same sign as $\Delta_{4}$, and is thus $\geq 0$.

\section{Proof of Proposition 5}

(a) The proof here follows the same idea as the previous proof (part (c)) of using the parametrized Cournot oligopoly with profit function given by (10). We show that the Cournot equilibrium profit $\pi(\alpha)$ is increasing in $\alpha$, under condition (5). This clearly implies our desired conclusion for reasons similar to those of the previous proof.

To this end, differentiate $\pi(\alpha)=x(\alpha)[P(z(\alpha), \alpha)-c]$ with respect to $\alpha$, and then use the first order condition for a Cournot equilibrium to simplify to

$$
\pi^{\prime}(\alpha)=-x \frac{-P_{1}\left(2 P_{2}+x P_{12}\right)+z\left(P_{1} P_{12}-P_{2} P_{11}\right)}{(n+1) P_{1}+z P_{11}}=-x \frac{\Delta_{5}(z)}{(n+1) P_{1}+z P_{11}}
$$

Since the denominator $(n+1) P_{1}+z P_{11}<0$ by Cournot stability, the desired conclusion follows.

(b) Consider the following inequalities

$$
\begin{aligned}
C S_{n}^{C}-C S_{n}^{I} & =\int_{0}^{n \bar{x}_{n}^{C}}\left[P\left(t, n \bar{x}_{n}^{C}\right)-P\left(n \bar{x}_{n}^{C}, n \bar{x}_{n}^{C}\right)\right] d t-\int_{0}^{n \bar{x}_{n}^{I}}\left[P\left(t, \bar{x}_{n}^{I}\right)-P\left(n \bar{x}_{n}^{I}, \bar{x}_{n}^{I}\right)\right] d t \\
& \geq \int_{0}^{n \bar{x}_{n}^{I}}\left[P\left(t, n \bar{x}_{n}^{C}\right)-P\left(n \bar{x}_{n}^{C}, n \bar{x}_{n}^{C}\right)\right] d t-\int_{0}^{n \bar{x}_{n}^{I}}\left[P\left(t, \bar{x}_{n}^{I}\right)-P\left(n \bar{x}_{n}^{I}, \bar{x}_{n}^{I}\right)\right] d t \\
& \geq \int_{0}^{n \bar{x}_{n}^{I}}\left[P\left(t, n \bar{x}_{n}^{C}\right)-P\left(n \bar{x}_{n}^{C}, n \bar{x}_{n}^{C}\right)\right] d t-\int_{0}^{n \bar{x}_{n}^{I}}\left[P\left(t, \bar{x}_{n}^{I}\right)-P\left(n \bar{x}_{n}^{C}, \bar{x}_{n}^{I}\right)\right] d t \geq 0 .
\end{aligned}
$$

The first and second inequalities follow from the facts that $\bar{x}_{n}^{C} \geq \bar{x}_{n}^{I}$ and $P_{1}(z, s)<0$. The last one is implied by the submodularity of $P$, i.e., the assumption that $P_{12}(z, s) \leq 0$. To see 
this, notice that $t \in\left[0, n \bar{x}_{n}^{I}\right]$ and $n \bar{x}_{n}^{C} \geq n \bar{x}_{n}^{I}$ imply that $n \bar{x}_{n}^{C} \geq t$, so that $P_{12}(z, s) \leq 0$ and $n \bar{x}_{n}^{C} \geq \bar{x}_{n}^{I}$ imply that $P\left(t, n \bar{x}_{n}^{C}\right)-P\left(t, \bar{x}_{n}^{I}\right) \geq P\left(n \bar{x}_{n}^{C}, n \bar{x}_{n}^{C}\right)-P\left(n \bar{x}_{n}^{C}, \bar{x}_{n}^{I}\right)$ for all $t \in\left[0, n \bar{x}_{n}^{I}\right]$.

(c) The social welfare function for any per-firm output $x$ and expected size of the network $s$ with $n$ symmetric firms is given by

$$
V_{n}(x, s)=\int_{0}^{n x} P(t, s) d t-n c x
$$

which is a concave function with respect to $x$ since $\frac{\partial^{2} V_{n}(x, s)}{\partial x^{2}}=n^{2} P_{1}(n x, s)<0$, by (A1). Then, we have that at the highest equilibria

$$
\begin{aligned}
W_{n}^{C}-W_{n}^{I} & =\left\{\int_{0}^{n \bar{x}_{n}^{C}} P\left(t, n \bar{x}_{n}^{C}\right) d t-n c \bar{x}_{n}^{C}\right\}-\left\{\int_{0}^{n \bar{x}_{n}^{I}} P\left(t, \bar{x}_{n}^{I}\right) d t-n c \bar{x}_{n}^{I}\right\} \\
& \geq\left\{\int_{0}^{n \bar{x}_{n}^{C}} P\left(t, n \bar{x}_{n}^{C}\right) d t-n c \bar{x}_{n}^{C}\right\}-\left\{\int_{0}^{n \bar{x}_{n}^{I}} P\left(t, n \bar{x}_{n}^{C}\right) d t-n c \bar{x}_{n}^{I}\right\} \\
& =V_{n}\left(\bar{x}_{n}^{C}, n \bar{x}_{n}^{C}\right)-V_{n}\left(\bar{x}_{n}^{I}, n \bar{x}_{n}^{C}\right) \\
& \geq \frac{\partial V_{n}\left(\bar{x}_{n}^{C}, n \bar{x}_{n}^{C}\right)}{\partial x}\left(\bar{x}_{n}^{C}-\bar{x}_{n}^{I}\right) \\
& =n\left[P\left(n \bar{x}_{n}^{C}, n \bar{x}_{n}^{C}\right)-c\right]\left(\bar{x}_{n}^{C}-\bar{x}_{n}^{I}\right) \geq 0
\end{aligned}
$$

The first inequality follows by $n \bar{x}_{n}^{C} \geq \bar{x}_{n}^{I}$ and $P_{2}(z, s)>0$; the second one, by concavity of $V_{n}(\cdot, s)$, and the last one, because $P\left(n \bar{x}_{n}^{C}, n \bar{x}_{n}^{C}\right) \geq c$ and $\bar{x}_{n}^{C} \geq \bar{x}_{n}^{I}$. This completes the proof of the Proposition.

\section{References}

Amir, R., 1996a, Cournot oligopoly and the theory of supermodular games, Games and Economic Behavior, 15, 132-148.

Amir, R., 1996b. Sensitivity analysis of multisector optimal economic dynamics, Journal of Mathematical Economics 25, 123-141.

Amir, R. and V. E. Lambson, 2000, On the effects of entry in Cournot markets, Review of Economic Studies, 67, 235-254.

Amir, R. and N. Lazzati, 2011, Network effects, market structure and industry performance, Journal of Economic Theory, 146, 2389-2419.

.Amir, R., L. Koutsougeras and L. De Castro, 2014, Free entry versus socially optimal entry, Journal of Economic Theory, 154, 112-125.

Armstrong, M., 2006, Competition in two-sided markets, The RAND Journal of Economics, 37, 668-691. 
Barthel, AC. and T. Sabarwal, 2018. Directional monotone comparative statics, Economic Theory, 66, 557-591.

Brandenburger, A. and B. Nalebuff, 1996, Co-opetition, Doubleday, New York.

Brécard, D., 2013, Environmental quality competition and taxation in the presence of green network effect among consumers, Environmental and Resource Economics, 54, 1-19.

Cosandier, C., F. Garcia, and M. Knauff, 2018. Price competition with differentiated goods and incomplete product awareness, Economic Theory, 66, 681-705.

Crémer, J., P. Rey and J. Tirole, 2000, Connectivity in the commercial Internet, Journal of Industrial Economics, 48, 433-472.

Cusumano, M. A., Mylonadis, Y. and R. S. Rosenbloom, 1992, Strategic maneuvering and mass-market dynamics: the triumph of VHS over Beta, The Business History Review, 66, 51-94. Church, J. and N. Gandal, 1992, Network effects, software provision, and standardization, The Journal of Industrial Economics, 40:85-103.

Echenique, F., 2002, Comparative statics by adaptive dynamics and the correspondence principle, Econometrica, 70, 833-844.

Filistrucchi, L., D. Geradin, E. Van Damme, P. Affeldt, 2014, Market definition in two-sided markets: Theory and practice, Journal of Competition Law $\&$ Economics 10, 293-339.

Fudenberg, D. and J. Tirole, 1991, Game Theory, The MIT Press, Cambridge, MA.

Gans, J., S.P. King, and J. Wright, 2005, Wireless Communications, Handbook of Telecommunications Economics, Vol II, Martin Cave et. al. (eds.), North-Holland: Amsterdam, 243-281. Garcia, F. and C. Vergari, 2015, Revealing incentives for compatibility provision in vertically differentiated network industries, Journal of Economics \& Management Strategy, 25, 720-749. Greaker, M. and K. Midttømme, 2016, Network effects and environmental externalities: Do clean technologies suffer from excess inertia? Journal of Public Economics, 143, 27-38.

Grilo, I., O. Shy, and J. Thisse, 2001, Price competition when consumer behavior is characterized by conformity or vanity, Journal of Public Economics, 80, 385-408.

Jullien, B., 2011, Competition in multi-sided markets: Divide and conquer, American Economic Journal: Microeconomics, 3, 186-220.

Katz, M. L. and C. Shapiro, 1985, Network externalities, competition and compatibility, American Economic Review, 75:424-440.

Katz, M. L. and C. Shapiro, 1986, Technology adoption in the presence or network externalities, Journal of Political Economy, 94:822-841. 
Laussel, D., N. Van Long, and J. Resende, 2015, Network effects, aftermarkets and Coase conjecture: a dynamic Markovian approach. International Journal of Industrial Organization, 41, 84-96.

Laussel, D. and J. Resende, 2014, Dynamic price competition in aftermarkets with network effects, Journal of Mathematical Economics, 50, 106-118.

Leibenstein, H., 1950, Bandwagon, snob, and Veblen effects in the theory of consumers' demand, Quarterly Journal of Economics, 64, 183-207.

Liebowitz, J. Margolis, S. E., 1994. Network externality: An uncommon tragedy, Journal of Economic Perspectives, 8, 133-150.

Luchetta, G., 2014, Is the google platform a two-sided market?, Journal of Competition Law $\mathcal{G}$ Economics, 10, 185-207.

Markovich, S. and J. Moenius, 2009, Winning while losing: competition dynamics in the presence of indirect network effects, International Journal of Industrial Organization, 27: 346-357.

Milgrom, P. and J. Roberts, 1990, Rationalizability, learning and equilibrium in games with strategic complementarities, Econometrica, 58, 1255-1278.

Resende, J., 2008, The economic advantage of being the "voice of the majority, Journal of Media Economics, 21, 158-190.

Rochet, J. C. and J. Tirole, 2006, Two-sided markets: a progress report, The RAND journal of economics, 37, 645-667.

Rohlfs, J., 1974, A theory of interdependent demand for a communications service, Bell Journal of Economics and Management Science, 5, 16-37.

Rohlfs, J., 2003, Bandwagon effects in high-technology industries, The MIT Press, Cambridge, MA.

Shapiro, C. and Varian, H. R., 1998, Information rules: A strategic guide to the network economy, Harvard Business School Press, Boston, MA.

Shy, O., 2001, The economics of network industries, Cambridge University Press: Cambridge. Topkis, D., 1998, Supermodularity and Complementarity, Princeton University Press, Princeton. Veblen, T. B., 1899, The theory of the leisure class, London: Macmillan.

Vives, X., 1990, Nash equilibrium with strategic complementarities, Journal of Mathematical Economics, 19, 305-321.

Vives, X., 1999, Oligopoly pricing: Old ideas and new tools, The MIT Press, Cambridge, MA. 